\title{
Risk factors for hamstring muscle strain injury in sport: a systematic review and meta-analysis
}

\author{
Grant Freckleton, Tania Pizzari
}

Department of Physiotherapy, La Trobe University, Melbourne, Australia

\section{Correspondence to} Tania Pizzari, La Trobe University, Department of Physiotherapy,

Bundoora, Mebourne, Victoria 3086, Australia; T.Pizzari@latrobe.edu.au

Received 11 October 2011 Accepted 9 May 2012 Published Online First 4 July 2012

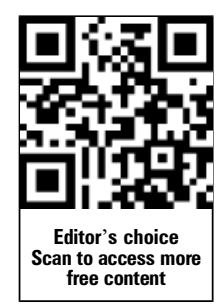

To cite: Freckleton $\mathrm{G}$, Pizzari T. Br J Sports Med 2013:47:351-358.

\section{INTRODUCTION}

Hamstring muscle strain-type injuries are common in sports that involve sprinting, ${ }^{1}$ acceleration, deceleration, rapid change in direction and jumping. ${ }^{2} 3$ Occurring in both recreational and professional sports, these injuries can result in substantial time lost from sport and commonly recur. ${ }^{45}$

In the Australian Football League (AFL), hamstring muscle strain-type injuries have displayed a high incidence rate, with a 10 year mean of 6.1 new injuries per club each year and a $23 \%$ average recurrence rate. $^{6}$ A recurrence rate of $17 \%$ has been reported in elite soccer players ${ }^{7}$ with hamstring injuries also recorded as the most common injury accounting for $12 \%$ of all injuries and resulting in an average of four missed games per injury. ${ }^{8}$

The high incidence of hamstring muscle straintype injuries and potential associated costs has resulted in a substantial amount of research into the factors related to such injuries. Two recent systematic reviews have been completed in an attempt to collate the evidence around risk factors for hamstring injuries. ${ }^{9}{ }^{10}$ Both reviews identified hamstring muscle weakness and thigh muscle imbalance, muscle flexibility, previous hamstring injury, other previous injury and age as potential risk factors; however, these reviews concluded that single variables were inconsistently identified as associated factors. Both reviews provided a qualitative synthesis of the literature and included risk factor studies as well as intervention studies, where a potential risk factor was modified with a training programme. The inclusion of intervention studies may potentially complicate risk factor analyses, as such studies assume that the factor being modified is associated with the injury and that the factor can be modified by the treatment programme.

The aim of the current review was to assemble all available knowledge and data to identify the intrinsic and extrinsic risk factors associated with hamstring muscle strain-type injuries in sport.

\section{METHODS}

\section{Search strategy and identification of studies}

A systematic literature search was conducted of Medline, CINAHL, Embase, AMED, AUSPORT, SPORTDiscus, PEDro and the Cochrane library from inception to August 2011. Where possible, key words (table 1) derived from the research question were mapped to subject headings (Supplemental file). To ensure all relevant articles were identified, citation tracking of all included articles was performed using Google Scholar, while reference scanning of the bibliographies of included articles was also performed. References yielded by the search were imported into Endnote X3
(Thomson Reuters, Newyork, USA) and duplicates were deleted.

\section{Study selection criteria}

To ensure consistent, unbiased selection of included studies, a set of inclusion and exclusion criteria were derived prior to database searching (table 2). Articles selected were limited to sports-related hamstring muscle strain-type injuries, not including tendon or avulsion injuries, as these commonly represent different pathological conditions and could be associated with alternative risk factors. Since the aim of this review was to identify the risk factors for hamstring injury, studies were required to have discrete data for hamstring injury, assessing some aspect of risk or associated factors.

Interventions that aimed to reduce the risk of sustaining a hamstring injury were excluded to limit the potential confounder of the effect of the intervention. Studies were also required to be prospective in nature. A retrospective design is unable to determine whether measured variables predisposed to, or were the result of, injury. ${ }^{11}$

Studies were required to be published in English and contain human participants. Articles were included if they were published in peer reviewed journals and full text was accessible. Abstracts from conferences and unpublished data were not included as the quality and rigor of such information may be questionable.

The titles and abstracts of each article in the Endnote library were analysed and selection criteria applied independently by two examiners (GF and TP). All articles determined to be potentially applicable were obtained in full text version. Criteria were reapplied to full text versions by both examiners in consultation.

\section{Data collection and analysis}

Assessing bias and methodological quality

Studies were not excluded based on quality. The purpose of the quality assessment was to examine the bias of each article rather than to specifically exclude any of them. The methodological quality of the included studies, except the systematic reviews, was evaluated by one examiner (GF) and checked by another examiner (TP) using a checklist validated for the assessment of the methodological rigor of both controlled and non-controlled studies. ${ }^{12}$ The checklist has demonstrated high internal consistency for non-randomised studies (Kuder Richardson-20 reliability coefficient $=$ $0.89)$ and good test-retest $(\mathrm{r}=0.88)$ and inter-rater $(\mathrm{r}=0.75)$ reliability. ${ }^{12}$

The original scale consists of 27 questions but for the purposes of this review each study was only 
Table 1 Keywords for search strategy

\begin{tabular}{llll}
\hline Population & Hamstring & Pathology/injury & Risk factors \\
\hline Athlet $^{*}$ & Semimembranosus & Tear & Risk \\
Sport & Semitendinosus & Strain & Risk factors \\
Exercise & Biceps femoris & Injur $^{*}$ & Caus* $^{*}$ \\
& Hamstring & & Pred $^{*}$ \\
& Posterior thigh & & \\
\hline *truncation. & & &
\end{tabular}

assessed on the most relevant questions. Questions 4, 8, 9, 13, $14,15,17,19,23,24,26$ and 27 relate to intervention studies and were not applied. Of the included items, questions 1, 2, 3, 5, 6, 7 and 10 regarded reporting of aims, methods, data and results. Questions 11 and 12 were concerned with the external validity of studies, while questions 16, 18, 20, 21, 22 and 25 assessed the internal validity and bias. This modified tool has been used previously in a systematic review of factors associated with heel pain. ${ }^{13}$ Quality assessment results were presented as a percentage score.

The Critical Appraisal Skills Programme (CASP) ${ }^{14}$ was used to assess the quality of the previously published systematic reviews. The tool was modified to include only the most relevant questions. Items 6 and 7 were omitted as they did not allow for a score to be applied.

\section{Data extraction}

Relevant data extracted included the type of sport, participant numbers, sample details, number of injuries, risk factors investigated and how they were measured, how hamstring injury was diagnosed, the length of tracking of participants, and the results, including statistical techniques used and statistical results.

\section{Data analysis}

Data including means, SD, RR, OR and HR were extracted independently by two non-blinded reviewers (GF, TP). For continuous data, standardised mean differences (SDM) and 95\% CI were calculated by dividing the injured and non-injured group means by the pooled SD. The SDM is a measure of the difference between players who sustained a hamstring injury and those who remained injury free. RR, OR and 95\% CI were

Table 2 Study selection criteria

\begin{tabular}{ll}
\hline Inclusion & Exclusion \\
\hline $\begin{array}{l}\text { Sports-related hamstring injuries } \\
\text { Hamstring muscle strain-type injury } \\
\text { (primary or recurrent hamstring } \\
\text { injuries) }\end{array}$ & $\begin{array}{l}\text { Tendon injuries and general, } \\
\text { non-specific studies into } \\
\text { musculoskeletal injury } \\
\text { Must have discrete data for hamstring } \\
\text { injury, assessing some aspect of risk, } \\
\text { either intrinsic, extrinsic or both } \\
\begin{array}{l}\text { Human subjects } \\
\text { Prospective studies }\end{array}\end{array}$ \\
$\begin{array}{ll}\text { hamstring injury } \\
\text { Peer reviewed journals and be able to }\end{array}$ & $\begin{array}{l}\text { Retrospective studies, opinion articles, } \\
\text { single case studies, cross sectional } \\
\text { studies, and non-systematic reviews } \\
\text { access full text }\end{array}$ \\
\begin{tabular}{l} 
English language \\
\hline
\end{tabular}
\end{tabular}

recalculated, where appropriate, from frequency tables of individual studies. The reported ratios were used when the studies did not provide adequate frequency data.

Where the data provided were appropriate, Comprehensive Meta-analysis Version 2.0 (BioStat, Englewood, New Jersey, USA) software was used to conduct a meta-analysis for the proposed risk factors for hamstring injury. To account for methodological or statistical heterogeneity, a random effects model was used. A random effects model makes no assumption about causes of variance in the sample distribution. It generates a wider CI around the pooled effect size than a fixed effects model, therefore it is less likely to find a significant effect and is considered a safer, more conservative option, with more accurate information obtained. ${ }^{15}$ Heterogeneity was assessed using the $\mathrm{I}^{2}$ statistic. ${ }^{16}$ This statistical test estimates the proportion of total variation in study estimates that is due to heterogeneity and is not dependent on the number of included studies. A value of $0 \%$ indicates no observed heterogeneity, less than $25 \%$ is considered to have low levels and a value of $100 \%$ indicates a completely heterogenous sample.

\section{RESULTS}

\section{Search results}

The initial search yielded 1649 articles, 600 duplicates were removed, leaving 1049 potentially relevant articles. After application of the selection criteria to titles and abstracts, full texts of 52 articles were retrieved and criteria applied to the full text. A final list of 26 relevant articles was formed, with citation tracking and reference scanning revealing a further 18 for review, of which eight were included. Reference scanning and citation tracking of the newly included eight articles resulted in no new relevant studies being found. A total of 36 articles were therefore excluded of the 70 retrieved after the initial search, citation tracking and reference scanning had been performed. Eight review articles were excluded because they were not systematic reviews. ${ }^{17-24}$ Another two studies were omitted as they were retrospective designs ${ }^{25} 26$ and a further 11 were excluded on the basis that they had no specific risk factor data for hamstring injury. $^{27-37}$ Six articles were excluded because they did not contain any discrete data regarding incidence or recurrence of hamstring muscle strain-type injury. ${ }^{38-43}$ Another two were excluded because they used an intervention programme, ${ }^{44} 45$ while a further six were excluded as they were either published abstracts $^{46-49}$ or not published in peer-reviewed journals. ${ }^{50} 51$ One case study was excluded. ${ }^{52}$ A total of 34 articles were included for review. $191053-83$

\section{Characteristics and quality of included studies}

Quality assessment scores for the included research studies ranged between 7 and 15 out of a possible 16 (table 3). Percentage scores ranged between 44 and 94\% (Mean=83\%).

Eleven articles 5455575962646971758081 did not report on the reliability and validity of the tests to examine risk factors and subsequently did not score on item 20 .

Twelve studies ${ }^{55} \quad 5960 \quad 62 \quad 66 \quad 7073 \quad 77 \quad 78 \quad 80-82$ did not use adequate adjustment for confounding variables, particularly previous injury and age. Without adequate adjustment for confounding variables, the results of some studies may not be accurate. The CASP quality scores for the systematic reviews demonstrated that all studies scored 7 out of a possible 8 on the scale (table 4).

Fourteen of the prospective studies included investigated hamstring muscle strain-type injuries in Australian football, $^{1} \quad 54 \quad 55 \quad 58 \quad 63-66 \quad 69 \quad 71 \quad 74-77 \quad 10$ studies investigated 
Table 3 Quality assessment scores for included studies

\begin{tabular}{|c|c|c|c|c|c|c|c|c|c|c|c|c|c|c|c|c|c|}
\hline \multirow[b]{2}{*}{ Study } & \multicolumn{17}{|c|}{ Question } \\
\hline & 1 & 2 & 3 & 5 & 6 & 7 & 10 & 11 & 12 & 16 & 18 & 20 & 21 & 22 & 25 & Total & $\%$ \\
\hline Arnason et $a F^{53}$ & 1 & 1 & 1 & 1 & 1 & 1 & 1 & 1 & 1 & 1 & 1 & 1 & 1 & 1 & 1 & 15 & 94 \\
\hline Bennell et $a l^{55}$ & 1 & 1 & 1 & 1 & 1 & 0 & 0 & 1 & 1 & 1 & 1 & 0 & 1 & 0 & 0 & 10 & 63 \\
\hline Bennell et al ${ }^{54}$ & 1 & 1 & 1 & 1 & 1 & 1 & 1 & 1 & 1 & 1 & 1 & 0 & 1 & 1 & 1 & 14 & 88 \\
\hline Bradley and Portas ${ }^{56}$ & 1 & 1 & 1 & 0 & 1 & 1 & 1 & 1 & 1 & 1 & 1 & 1 & 1 & 1 & 1 & 14 & 88 \\
\hline Brooks et $a^{57}$ & 1 & 1 & 1 & 1 & 1 & 1 & 1 & 1 & 1 & 1 & 1 & 0 & 1 & 1 & 1 & 14 & 88 \\
\hline Cameron et $a l^{58}$ & 1 & 1 & 1 & 1 & 1 & 1 & 1 & 1 & 1 & 1 & 1 & 1 & 1 & 1 & 1 & 15 & 94 \\
\hline Christensen and Wiseman ${ }^{59}$ & 1 & 1 & 1 & 0 & 0 & 0 & 0 & 1 & 0 & 1 & 0 & 0 & 1 & 1 & 0 & 7 & 44 \\
\hline Croisier et $a /^{60}$ & 1 & 1 & 1 & 0 & 1 & 1 & 0 & 1 & 0 & 1 & 1 & 1 & 1 & 0 & 0 & 10 & 63 \\
\hline Engbertsen $^{61}$ & 1 & 1 & 1 & 1 & 1 & 1 & 1 & 1 & 1 & 1 & 1 & 1 & 0 & 1 & 1 & 14 & 88 \\
\hline Fousekis et $a l^{62}$ & 1 & 1 & 1 & 1 & 1 & 1 & 1 & 1 & 1 & 1 & 1 & 0 & 1 & 1 & 0 & 13 & 81 \\
\hline Gabbe et $a l^{65}$ & 1 & 1 & 1 & 1 & 1 & 1 & 1 & 1 & 1 & 1 & 1 & 1 & 1 & 1 & 1 & 15 & 94 \\
\hline Gabbe et a/63 & 1 & 1 & 1 & 2 & 1 & 1 & 1 & 1 & 1 & 1 & 1 & 1 & 0 & 0 & 1 & 14 & 88 \\
\hline Gabbe et $a l^{64}$ & 1 & 1 & 1 & 1 & 1 & 1 & 1 & 1 & 1 & 1 & 1 & 0 & 1 & 1 & 1 & 14 & 88 \\
\hline Gibbs et $a^{66}$ & 1 & 1 & 1 & 1 & 1 & 1 & 1 & 1 & 1 & 1 & 1 & 1 & 1 & 0 & 0 & 13 & 81 \\
\hline Hagglund $^{67}$ & 1 & 1 & 1 & 1 & 1 & 1 & 1 & 1 & 1 & 1 & 0 & 1 & 1 & 1 & 1 & 14 & 88 \\
\hline Henderson et $a l^{68}$ & 1 & 1 & 1 & 1 & 1 & 1 & 0 & 1 & 1 & 1 & 1 & 1 & 1 & 1 & 1 & 14 & 88 \\
\hline Koulouris et a/69 & 1 & 0 & 1 & 1 & 1 & 1 & 1 & 1 & 1 & 1 & 1 & 0 & 1 & 1 & 1 & 13 & 81 \\
\hline Malliaropoulos et $a l^{70}$ & 1 & 1 & 1 & 0 & 1 & 1 & 1 & 1 & 0 & 1 & 1 & 1 & 1 & 1 & 0 & 12 & 75 \\
\hline Orchard et al ${ }^{1}$ & 1 & 1 & 1 & 1 & 1 & 1 & 1 & 1 & 1 & 1 & 1 & 1 & 1 & 1 & 1 & 15 & 94 \\
\hline $\operatorname{Orchard}^{71}$ & 1 & 1 & 1 & 2 & 1 & 1 & 1 & 1 & 1 & 1 & 1 & 0 & 1 & 1 & 1 & 15 & 94 \\
\hline Rolls and George ${ }^{72}$ & 1 & 1 & 1 & 1 & 1 & 1 & 0 & 1 & 1 & 1 & 1 & 1 & 1 & 1 & 1 & 14 & 88 \\
\hline Sugiura et $a l^{73}$ & 1 & 1 & 1 & 1 & 1 & 1 & 1 & 1 & 1 & 1 & 1 & 1 & 1 & 0 & 0 & 13 & 81 \\
\hline Verrall et $a l^{75}$ & 1 & 1 & 1 & 1 & 1 & 1 & 1 & 1 & 1 & 1 & 1 & 0 & 1 & 1 & 1 & 14 & 88 \\
\hline Verrall et $a l^{71}$ & 1 & 1 & 1 & 1 & 1 & 1 & 1 & 1 & 1 & 1 & 1 & 1 & 1 & 1 & 1 & 15 & 94 \\
\hline Warren et $a l^{76}$ & 1 & 1 & 1 & 1 & 1 & 1 & 1 & 1 & 1 & 1 & 1 & 1 & 1 & 1 & 1 & 15 & 94 \\
\hline Watsford et $a l^{77}$ & 1 & 1 & 1 & 0 & 1 & 0 & 1 & 1 & 1 & 1 & 1 & 1 & 1 & 1 & 0 & 12 & 75 \\
\hline Witvrouw et al ${ }^{78}$ & 1 & 1 & 1 & 0 & 1 & 1 & 1 & 1 & 1 & 1 & 1 & 1 & 1 & 1 & 0 & 13 & 81 \\
\hline Woods et al9 & 1 & 1 & 1 & 1 & 1 & 0 & 0 & 1 & 1 & 1 & 1 & 1 & 1 & 1 & 1 & 13 & 81 \\
\hline Yamada and Mastumoto ${ }^{80}$ & 1 & 1 & 1 & 1 & 1 & 0 & 1 & 1 & 1 & 1 & 1 & 0 & 1 & 1 & 0 & 12 & 75 \\
\hline Yamamoto $^{81}$ & 1 & 1 & 1 & 0 & 1 & 1 & 0 & 1 & 1 & 1 & 1 & 0 & 1 & 1 & 0 & 11 & 69 \\
\hline Yeung et $a l^{82}$ & 1 & 1 & 1 & 1 & 1 & 1 & 1 & 1 & 1 & 1 & 1 & 1 & 0 & 1 & 0 & 13 & 81 \\
\hline
\end{tabular}

soccer, ${ }^{53} 56$ 60-62 6768727879 five studies investigated track and field ${ }^{59} 70738182$ while two studies investigated rugby. ${ }^{5780}$ The follow-up period varied between 3 weeks and 8 years (Supplemental file).

\section{Evaluation of risk factors}

Age

Seventeen studies investigated the influence of age as a risk factor for hamstring muscle strain-type injuries. $^{1} 53576162646567-6971$ 74-77 7982 Seven studies (3199 participants) were included in a meta-analysis using SDM data and three using RR data (figures 1 and 2). The results support age as a significant risk factor for injury $(\mathrm{SDM}=2.5,95 \% \mathrm{CI}$ 0.78 to $\left.4.15, p=0.004, I^{2}=99 \%\right)$. Figure 2 illustrates that

Table 4 Systematic review quality assessment

\begin{tabular}{|c|c|c|c|c|c|c|c|c|c|c|}
\hline \multirow[b]{2}{*}{ Study } & \multicolumn{10}{|c|}{ Items } \\
\hline & 1 & 2 & 3 & 4 & 5 & 8 & 9 & 10 & Total & $\%$ \\
\hline Emery $\mathrm{C}^{83}$ & 1 & 1 & 0 & 1 & 1 & 1 & 1 & 1 & 7 & 87.5 \\
\hline Foreman et $a l^{9}$ & 1 & 1 & 1 & 1 & 1 & 0 & 1 & 1 & 7 & 87.5 \\
\hline Prior et $a l^{10}$ & 1 & 1 & 0 & 1 & 1 & 1 & 1 & 1 & 7 & 87.5 \\
\hline
\end{tabular}

athletes of older age tended to be at increased risk of sustaining a hamstring injury $(\mathrm{OR}=2.46,95 \%$ CI 0.98 to $6.14, \mathrm{p}=0.06$, $\left.\mathrm{I}^{2}=73 \%\right)$.

Of the seven studies not included in the meta-analyses, two found age to be a significant risk factor for hamstring muscle strain-type injuries. Hagglund et $a l^{67}$ found age $(\mathrm{HR}=1.1,95 \%$ CI 1.0 to $1.2, p=0.02$ ) to be a significant risk factor, while Woods $e t a l^{79}$ found 17-22 year old age groups sustained fewer hamstring strains than the older soccer players $(p<0.01)$. Two studies reported that age was not a significant factor for injury $^{157}$ and a further three studies found that age was not associated with injury recurrence. ${ }^{69} 7476$

\section{Body mass index/height/weight/body composition}

Body mass index (BMI)

Seven studies (835 participants) evaluated the effect of BMI on hamstring muscle strain-type injuries. $\begin{array}{lllllll}53 & 57 & 61 & 64 & 67 & 74 & 80\end{array}$ Meta-analysis using three studies ${ }^{53} 6180$ demonstrated no association between $\mathrm{BMI}$ and hamstring injury (SDM $=1.28,95 \% \mathrm{CI}$ -1.35 to $\left.3.90, \mathrm{p}=0.34, \mathrm{I}^{2}=98 \%\right)$.

In agreement with the results of the meta-analysis, BMI was not found to be associated with hamstring injuries in a group of rugby players, ${ }^{57}$ nor was it associated with recurrent hamstring injuries. ${ }^{67} 74$ Of the four studies not included in the meta-analysis, only Gabbe et $a l^{64}$ showed that BMI $>25$ was 
Study name Comparison

\begin{tabular}{llrrrrrrrr} 
Study name & \multicolumn{2}{c}{ Comparison } & \multicolumn{7}{c}{ Statistics for each study } \\
& & & $\begin{array}{c}\text { Std diff } \\
\text { in means }\end{array}$ & $\begin{array}{c}\text { Standard } \\
\text { error }\end{array}$ & Variance & Lower & limit & Upper \\
limit & Z-Value p-Value \\
Fousekis 2011 & Age & -0.018 & 0.273 & 0.075 & -0.553 & 0.518 & -0.064 & 0.949 \\
Yeung 2009 & Age & 0.512 & 0.395 & 0.156 & -0.262 & 1.285 & 1.297 & 0.195 \\
Henderson 2010 & Age & 1.216 & 0.413 & 0.171 & 0.406 & 2.026 & 2.943 & 0.003 \\
Engebretsen 2010 & Age & 0.123 & 0.074 & 0.006 & -0.023 & 0.269 & 1.652 & 0.098 \\
Arnason 2004 & Age & 13.783 & 0.615 & 0.378 & 12.578 & 14.988 & 22.422 & 0.000 \\
Verrall 2001 & Age & 0.968 & 0.232 & 0.054 & 0.513 & 1.423 & 4.167 & 0.000 \\
Watsford 2010 & Age & 1.261 & 0.292 & 0.085 & 0.688 & 1.834 & 4.312 & 0.000 \\
& & 2.461 & 0.860 & 0.739 & 0.777 & 4.146 & 2.864 & 0.004
\end{tabular}

associated with hamstring muscle strain-type injuries $(\mathrm{RR}=2.41$, $95 \% \mathrm{CI}, 1.25$ to $4.66, \mathrm{p}=0.01)$.

\section{Weight}

Fifteen studies evaluated the influence of weight on hamstring muscle strain-type injuries in 762 athletes. $^{1} 53 \quad 5761 \quad 626467 \quad 6971$ 74-77 $80 \quad 82$ The seven studies included in the meta-analysis did not demonstrate a difference in weight between the injured and non-injured groups, although there was a trend towards heavier athletes being more susceptible to hamstring injury $(\mathrm{SDM}=0.94,95 \% \mathrm{CI}-0.059$ to 1.19 , $\mathrm{p}=0.07, \mathrm{I}^{2}=97 \%$ ) (figure 3 ).

Two other studies found no association between weight and hamstring muscle strain-type injuries, ${ }^{15}$ while four studies did not find any correlation between weight and recurrent hamstring injury. ${ }^{67} 697476$ However, two studies ${ }^{64} 71$ did demonstrate an association between weight and hamstring muscle strain-type injuries, although Gabbe et $a l^{64}$ identified this association only in football players aged $\geq 25$ years. They reported that for each kilogram increase in body weight, the risk of sustaining a hamstring injury increased by $7 \%$. Since BMI has been correlated with player age and previous injury, this association may be confounded by these variables. ${ }^{71}$

\section{Height}

Fifteen studies (1557 participants) investigated height as a risk $\begin{array}{lllllllllllll}\text { factor. }^{1} & 53 & 57 & 61 & 62 & 64 & 65 & 67 & 69 & 74-77 & 80 & 82 & \text { Seven }\end{array}$ studies $^{53} 61 \quad 62 \quad 75 \quad 778082$ were eligible for meta-analysis using the SMD and two studies were included in a RR meta-analysis. ${ }^{64} 65$ Standardised mean difference meta-analysis suggested height did not differ between groups of injured and non-injured players (SDM $=-0.03,95 \%$ CI -0.12 to 0.18 , $\left.\mathrm{p}=0.72, \mathrm{I}^{2}=8 \%\right)$. For the RR analysis, height was not found to be a risk factor for hamstring muscle strain-type injuries $\left(\mathrm{RR}=1.52,95 \%\right.$ CI 0.76 to $\left.3.03, \mathrm{p}=0.24, \mathrm{I}^{2}=0\right)$.

Of the six studies not included in the analysis, height was not significantly associated with first time ${ }^{157}$ or recurrent hamstring injury. 67697476

\section{Strength}

$H: Q$ ratio

A meta-analysis was completed using five studies ${ }^{1} \begin{array}{lllll}55 & 58 & 68 & 80\end{array}$ that measured conventional concentric $\mathrm{H}: \mathrm{Q}$ ratio. The analysis included 216 athletes and assessed the results of isokinetic testing at a slow speed $(60 \% \mathrm{sec})$. The meta-analysis demonstrated no difference between groups $(\mathrm{SDM}=-0.50,95 \% \mathrm{CI}$ -1.17 to $0.18, \mathrm{p}=0.15, \mathrm{I}^{2}=70 \%$ ), (figure 4 ).

Studies have used a number of other methods to measure $\mathrm{H}$ : $\mathrm{Q}$ ratio, varying the speed of testing and type of muscle contraction. Yeung et $a l^{82}$ identified that the risk of hamstring muscle strain-type injuries increased with a decrease in conventional concentric $\mathrm{H}$ : Q ratio at $180 \% \mathrm{sec}$. A ratio of less than 0.6 was found to increase injury risk by 17 times $(\mathrm{HR}=17.4,95 \% \mathrm{CI}$ 1.31 to $231.4, p=0.03)$. However, ratios tested at slower speeds and using different concentric/eccentric combinations in the same study were not identified as risk factors. Similarly, Bennell et $a l^{55}$ found $\mathrm{H}: \mathrm{Q}$ ratios could not predict hamstring muscle strain-type injuries despite measuring ratios at varying speeds and using differing combinations of eccentric and concentric contractions. In addition, Orchard et $a l^{1}$ found concentric H:Q

\begin{tabular}{llrrrrrr} 
Study name Comparison & \multicolumn{6}{c}{ Statistics for each study } \\
\cline { 3 - 5 } & & $\begin{array}{l}\text { Risk } \\
\text { ratio }\end{array}$ & $\begin{array}{l}\text { Lower } \\
\text { limit }\end{array}$ & $\begin{array}{l}\text { Upper } \\
\text { limit }\end{array}$ & Z-Value p-Value \\
Gabbe 2005 & Age >23yrs & 3.800 & 1.065 & 13.557 & 2.057 & 0.040 \\
Orchard 2001 & Age >23yrs & 1.340 & 1.142 & 1.573 & 3.585 & 0.000 \\
Gabbe 2006 & Age >25yrs & 4.430 & 1.569 & 12.510 & 2.810 & 0.005 \\
& & 2.457 & 0.983 & 6.142 & 1.923 & 0.055
\end{tabular}

Risk ratio and $95 \% \mathrm{Cl}$
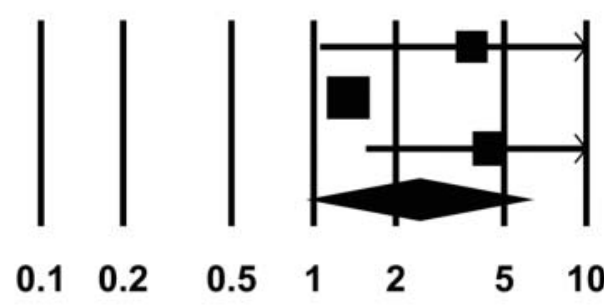

Younger athlete

Figure 2 RR for age as a risk factor. 
Study name Comparison

\begin{tabular}{|c|c|c|c|c|c|c|c|c|}
\hline & & $\begin{array}{l}\text { Std diff } \\
\text { in means }\end{array}$ & $\begin{array}{l}\text { Standard } \\
\text { error }\end{array}$ & Variance & $\begin{array}{c}\text { Lower } \\
\text { limit }\end{array}$ & $\begin{array}{c}\text { Upper } \\
\text { limit }\end{array}$ & Z-Value & p-Value \\
\hline Fousekis 2011 & Weight & 0.553 & 0.276 & 0.076 & 0.012 & 1.093 & 2.003 & 0.045 \\
\hline Engebretsen 2010 & Weight & 0.027 & 0.087 & 0.008 & -0.144 & 0.198 & 0.309 & 0.757 \\
\hline Arnason 2004 & Weight & 4.482 & 0.332 & 0.110 & 3.832 & 5.132 & 13.513 & 0.000 \\
\hline Verrall 2001 & Weight & 0.228 & 0.224 & 0.050 & -0.211 & 0.666 & 1.017 & 0.309 \\
\hline Watsford 2010 & Weight & 0.082 & 0.282 & 0.080 & -0.471 & 0.636 & 0.292 & 0.770 \\
\hline Yamada 2009 & Weight & -0.414 & 0.487 & 0.237 & -1.369 & 0.541 & -0.849 & 0.396 \\
\hline \multirow[t]{2}{*}{ Yeung et al 2009} & Weight & 1.636 & 0.428 & 0.183 & 0.798 & 2.475 & 3.823 & 0.000 \\
\hline & & 0.936 & 0.508 & 0.258 & -0.059 & 1.932 & 1.843 & 0.065 \\
\hline
\end{tabular}

Statistics for each study
Std diff in means and $95 \% \mathrm{Cl}$
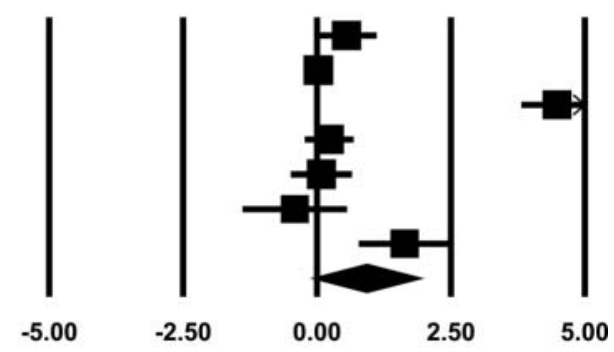

Lighter athlete
Figure 3 Standardised mean difference and $95 \% \mathrm{Cl}$ for weight as a risk factor. ratios at $180 \% \mathrm{sec}$ and $300 \% \mathrm{sec}$ were not different between injured and non-injured groups despite being significantly different at $60 \%$ sec. Overall, the evidence for isokinetic $\mathrm{H}: \mathrm{Q}$ ratio being a risk factor for hamstring muscle strain-type injuries is sparse when considered in isolation regardless of the speed and contraction type.

Croisier $e t a l^{60}$ found that identifying an imbalance profile (ie, a player who has a deficit on two or more isokinetic tests) was an effective method of identifying at-risk players. Soccer players were 4.66 times more likely to sustain a hamstring muscle strain-type injury $(\mathrm{OR}=4.66,95 \% \mathrm{CI} 2.01$ to 10.8$)$ if they were classified as having a strength imbalance in the preseason. Fousekis et $a l^{62}$ and Sugiura et $a l^{73}$ were also interested in imbalances of isokinetic strength and ratio tests between each leg of participants. Both studies used functional $\mathrm{H}: \mathrm{Q}$ ratios (eccentric hamstrings to concentric quadriceps) and Suguira et al tested at speeds of 60,180 and $300 \%$, while Fousekis et al tested only at $180 \%$ s. Functional $\mathrm{H}: \mathrm{Q}$ ratio asymmetry between legs was identified as a risk factor only when measured at the slower speed of $60 \%$ s.

None of the studies that utilised isokinetic dynamometry examined isometric $\mathrm{H}: \mathrm{Q}$ ratios, however two older studies used strain gauges to examine isometric $\mathrm{H}: \mathrm{Q}$ ratios and did find that a decrease in this ratio was a risk factors for hamstring muscle strain-type injuries. ${ }^{5981}$

\section{Hamstring peak torque}

Four studies (195 participants) gathered data for hamstring peak torque (concentric) values. ${ }^{1} 55^{58} 68 \mathrm{~A}$ meta-analysis including all four studies did not support hamstring peak torque as a risk factor for hamstring muscle strain-type injuries (SDM $=-0.24$, $95 \%$ CI -0.85 to $\left.0.37, \mathrm{p}=0.44, \mathrm{I}^{2}=58 \%\right)$. Bennell et $a l^{55}$ also analysed eccentric hamstring peak torque but did not find any significant difference between groups.

\section{Quadriceps peak torque}

Four studies (195 participants) assessed quadriceps peak torque. ${ }^{1555868}$ A meta-analysis supported an increase in quadriceps peak torque as a risk factor for hamstring muscle straintype injuries $\left(\mathrm{SDM}=0.43,95 \% \mathrm{CI} 0.05\right.$ to $\left.0.81, \mathrm{p}=0.03, \mathrm{I}^{2}=0\right)$ (figure 5). Bennell et $a l^{55}$ also analysed eccentric quadriceps peak torque in Australian football players but did not find any difference between those who sustained a hamstring injury and those who did not.

\section{Hamstring to opposite hamstring ratio}

Risk of hamstring strain increased with a lower hamstring to opposite hamstring $\left(\mathrm{H}: \mathrm{H}^{\mathrm{opp}}\right)$ concentric ratio at $60 \% \mathrm{~s}(\mathrm{p}=0.00)$ in an Australian football population. ${ }^{1}$ While eccentric hamstring strength asymmetries were predictive of hamstring muscle straintype injuries in soccer players $(\mathrm{OR}=3.88,95 \% \mathrm{CI} 1.13$ to 13.23, $\mathrm{p}=0.03$ ), however concentric strength asymmetries were not. $^{62}$ In another study of Australian football players, there were no differences in $\mathrm{H}: \mathrm{H}^{\text {opp }}$ ratios between injured and non-injured groups regardless of the speed of isokinetic testing or type of contraction, except for eccentric $180 \%$ shere a ratio greater than 0.90 was found to be predictive of injury $(\mathrm{p}=0.02) .{ }^{55}$

\section{Other strength measures}

Engebretsen et al ${ }^{61}$ found that a simple eccentric strength test was not associated with an increased risk of hamstring muscle strain-type injuries. Sugiura et $a l^{73}$ identified that weakness during concentric contraction of the hip extensors was associated with hamstring injury, but only when tested at $60 \%$ s.

\begin{tabular}{|c|c|c|c|c|c|c|c|c|}
\hline \multirow[t]{2}{*}{ Study name } & \multirow[t]{2}{*}{ Compari: } & \multicolumn{7}{|c|}{ Statistics for each study } \\
\hline & & $\begin{array}{l}\text { Std diff } \\
\text { in means }\end{array}$ & $\begin{array}{c}\text { Standard } \\
\text { error }\end{array}$ & Variance & $\begin{array}{c}\text { Lower } \\
\text { limit }\end{array}$ & $\begin{array}{c}\text { Upper } \\
\text { limit }\end{array}$ & Z-Value & p-Value \\
\hline Hendereson 2010 & $\mathrm{H}: \mathrm{Q}$ ratio & -0.178 & 0.375 & 0.140 & -0.912 & 0.557 & -0.474 & 0.636 \\
\hline Yamada 2009 & $\mathrm{H}: \mathrm{Q}$ ratio & 0.322 & 0.486 & 0.236 & -0.629 & 1.274 & 0.664 & 0.507 \\
\hline Orchard 1997 & $\mathrm{H}: \mathrm{Q}$ ratio & -1.596 & 0.483 & 0.233 & -2.543 & -0.649 & -3.304 & 0.00 \\
\hline Cameron 2003 & $\mathrm{H}: \mathrm{Q}$ ratio & -1.280 & 0.528 & 0.279 & -2.316 & -0.245 & -2.424 & 0.0 \\
\hline \multirow[t]{2}{*}{ Bennell 1998} & $\mathrm{H}: \mathrm{Q}$ ratio & 0.000 & 0.307 & 0.094 & -0.602 & 0.602 & 0.000 & $1.00 \mathrm{c}$ \\
\hline & & -0.498 & 0.344 & 0.118 & -1.172 & 0.176 & -1.447 & 0.14 \\
\hline
\end{tabular}

Std diff in means and $95 \% \mathrm{Cl}$

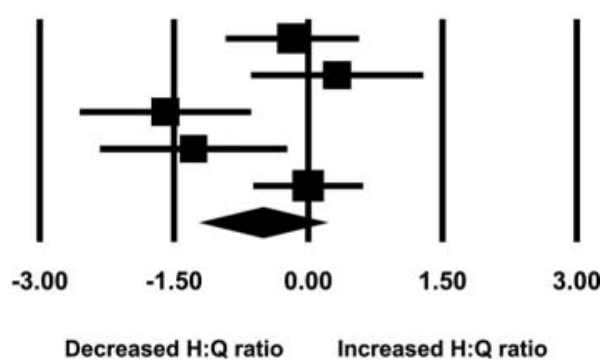

Figure 4 Standardised mean difference and $95 \% \mathrm{Cl}$ for concentric hamstring: quadriceps ratio. 
Study name Comparison

\begin{tabular}{|c|c|c|c|c|c|c|c|c|}
\hline & & $\begin{array}{l}\text { Std diff } \\
\text { in means }\end{array}$ & $\begin{array}{c}\text { Standard } \\
\text { error }\end{array}$ & Variance & $\begin{array}{c}\text { Lower } \\
\text { limit }\end{array}$ & $\begin{array}{c}\text { Upper } \\
\text { limit }\end{array}$ & Z-Value & p-Val \\
\hline Henderson 2010 & Quad peak torque & 0.214 & 0.375 & 0.141 & -0.522 & 0.949 & 0.569 & 0.5 \\
\hline Orchard 1997 & Quad peak torque & 0.145 & 0.446 & 0.199 & -0.730 & 1.020 & 0.325 & 0.7 \\
\hline Cameron 2003 & Quad peak torque & 1.119 & 0.519 & 0.269 & 0.102 & 2.136 & 2.156 & 0.0 \\
\hline \multirow[t]{2}{*}{ Bennell 1998} & Quad peak torque & 0.469 & 0.309 & 0.096 & -0.137 & 1.075 & 1.517 & 0.1 \\
\hline & & 0.430 & 0.195 & 0.038 & 0.048 & 0.812 & 2.205 & \\
\hline
\end{tabular}

Std diff in means and $95 \% \mathrm{Cl}$

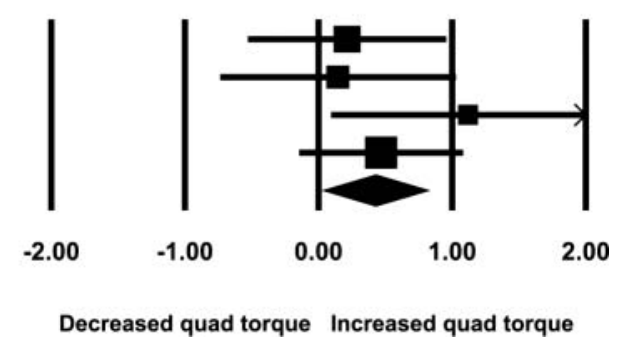

Figure 5 Standardised mean difference and $95 \% \mathrm{Cl}$ for quadriceps peak torque as a risk factor.

\section{Previous injury}

\section{Previous hamstring injury}

Thirteen studies reported on previous hamstring injury as a potential risk factor in hamstring muscle strain-type injuries. ${ }^{1} 535561626467-697175-77$ Meta-analysis including 2952 athletes supports the conclusion of previous hamstring injury being a risk factor for future injury $(\mathrm{RR}=2.68,95 \%$ CI 1.99 to $3.61, \mathrm{p}=0.00)^{64} 7176$ and $(\mathrm{OR}=4.06,95 \%$ CI 2.39 to 6.89 , $\mathrm{p}=0.00){ }^{53} 617577$ Heterogeneity was low across studies for OR $\left(I^{2}=29 \%\right)$ and $R R\left(I^{2}=22 \%\right)$.

In addition, Bennell et $a l^{55}$ found that Australian football players with a previous history of hamstring muscle strain-type injuries were 2.1 times more likely to sustain another hamstring injury $(\mathrm{p}=0.02)$ and Hagglund $e t \mathrm{al}^{67}$ reported a HR of 3.5 $(95 \%$ CI 1.9 to $6.5, \mathrm{p}=0.00)$ for elite soccer players who had experienced a previous hamstring injury. Koulouris $e a^{6 l^{69}}$ identified a trend towards increasing risk of recurrence with a history of previous hamstring muscle strain-type injury $(p=0.07)$. Only two studies did not find an association with previous hamstring injury ${ }^{1}{ }^{68}$ and one study found a past history of hamstring injury to be protective against recurrence $(\mathrm{OR}=0.15,95 \%$ CI 0.29 to $0.79, \mathrm{p}=0.02){ }^{62}$

\section{Other previous injuries}

Interestingly, three studies identified other injuries to be associated with hamstring muscle strain-type injuries. Koulouris et $a l^{69}$ demonstrated an association between history of ACL reconstruction and recurrent hamstring injury $(\mathrm{p}=0.00)^{69}$, Orchard $^{70}$ found that history of calf muscle strain (more than 8 weeks previously) was associated with risk of hamstring injury $(\mathrm{RR}=1.37,95 \% \mathrm{CI} 1.08$ to 1.76$)$, while Verrall et $a l^{74}$ reported that hamstring injury was associated with a past history of knee injury $(\mathrm{p}=0.04)$ and a past history of osteitis pubis.

\section{Flexibility and range of motion}

\section{Length and flexibility of hamstring}

Five studies assessed the length of the hamstring muscle as a risk factor using the active knee extension (AKE) test. ${ }^{64} 65707276$ The meta-analysis (407 participants) of two of these studies ${ }^{6465}$ did not identify AKE hamstring length results as a risk factor. $\left(\mathrm{RR}=1.89,95 \% \mathrm{CI} 0.93\right.$ to $\left.3.83, \mathrm{p}=0.08, \mathrm{I}^{2}=0\right)$.

Of the three studies not included in the meta-analysis, Rolls and George ${ }^{72}$ found no statistically significant relationship between poor hamstring flexibility and hamstring muscle straintype injuries in young soccer players, and Warren et $a l^{76}$ found no association with recurrence ( $\mathrm{RR}=1.4,95 \% \mathrm{CI} 0.8$ to 2.6 , $\mathrm{p}=0.27$ ). Malliaropoulos $e t a l^{70}$ reported that recurrent hamstring injuries were more likely in athletes with an AKE deficit of 10-19 degrees at $48 \mathrm{~h}$ after the initial injury, compared with larger and smaller AKE deficits.

Three studies measured hamstring length using the passive knee extension (PKE) test. ${ }^{536172} \mathrm{~A}$ total of 907 participants were included in the meta-analysis. There was no significant difference between the injured and non-injured groups $(\mathrm{SDM}=1.13,95 \% \mathrm{CI}-1.08$ to $3.35, \mathrm{p}=0.32)$. There was significant heterogeneity across the studies $\left(\mathrm{I}^{2}=99 \%\right)$. Fousekis et $a l^{62}$ also found no association between bilateral asymmetries in hamstring length and hamstring muscle strain-type injuries. In contrast, two studies established that a reduced mean ROM for the knee flexors increased the chance of hamstring injuries occurring in soccer players. ${ }^{5678}$

In addition, another study showed mean hamstring musculotendinous stiffness $(p=0.04)$ and mean leg stiffness $(p=0.03)$ were greater in AFL players who subsequently sustained a hamstring muscle strain-type injury. ${ }^{77}$

\section{Other range of motion tests}

Three studies found reduced hip extension ROM (or reduced hip flexor length) to be associated with subsequent hamstring injury. ${ }^{56} 6368$ Gabbe $e t$ al $l^{63}$ identified that for each $1^{\circ}$ increase on the modified Thomas test (ie, decreasing hip flexor flexibility), the risk of hamstring muscle strain-type injury increased $15 \%$ in players aged $\geq 25$ years. Hip internal and external ROM was not associated with injury $(\mathrm{p}>0.05){ }^{64}$

There is some evidence for an increased probability of sustaining a hamstring injury with decreased quadriceps flexibility $^{65} 78$ or dorsiflexion lunge ROM (RR $=2.32,95 \%$ CI, 0.97 to 5.56, $\mathrm{p}=0.05) .{ }^{64}$ However, bilateral asymmetries in flexibility for the quadriceps and plantar flexor muscles were not shown to be risk factors for injury. ${ }^{62}$ Slump test, ${ }^{64}{ }^{76}$ lumbar spine flexion, lumbo-femoral ratio, ${ }^{54}$ straight leg raise, ${ }^{76} 82$ and sit and reach test results, ${ }^{1}{ }^{54}$ were not significantly different between athletes who subsequently went on to strain a hamstring or suffer a recurrence and those who did not.

\section{MRI data}

Three studies assessed hamstring muscle strain-type injuries with MRI to determine risk factors for re-injury. ${ }^{66} 6974$ Athletes with an injury volume greater than $21.8 \mathrm{~cm}^{3}$ were 2.3 times more likely to be reinjured ( $95 \% \mathrm{CI}, 0.94$ to $5.81, \mathrm{p}=0.04)$ and an MRI-measured injury transverse size greater than $55 \%$ were 2.2 times $(95 \% \mathrm{CI}, 0.88$ to $5.32, \mathrm{p}=0.02)$ more likely to be reinjured. ${ }^{74}$ Although Verrall et $a l^{74}$ did find the cross sectional area (CSA) of the injured tissue on MRI to be significantly associated with risk of recurrent hamstring injury, both Koulouris et al $l^{69}$ and Gibbs et $a l^{66}$ found no association between CSA or length of injury on MRI and risk of recurrent injury. 
Convalescent interval, injury location, principal muscle injured, and the number of muscles injured were not associated with the risk for recurrent injury within the same playing season. $^{74}$

\section{Limb dominance}

No significant differences were observed in the number of hamstring injuries between the dominant and the non-dominant leg. ${ }^{1687478}$ In addition, preferred kicking leg did not correlate with injury in Australian football players. ${ }^{1}$

\section{Playing position}

The incidence of hamstring muscle strain-type injuries in rugby union was significantly higher for backs (8.6 injuries/1000 player hours; 95\% CI, 6.5 to 10.6 ) than for forwards (3.0 injuries/1000 player hours; $95 \%$ CI, 1.9 to 4.1$),{ }^{57}$ while soccer goalkeepers sustained significantly fewer injuries than outfield players $(\mathrm{p}<0.01){ }^{79}$

\section{Functional measures}

Ten studies looked at a variety of different functional measures to try and identify athletes who may be at risk of hamstring muscle strain-type injuries. Movement discrimination scores were worse in the subsequently injured group compared to the non-injured group $(\mathrm{p}=0.01),{ }^{58}$ while subsequent hamstring injury in university rugby players could be predicted by a slower time on a motor imagery task. ${ }^{80}$ For the non-counter movement jump test, the odds of sustaining an injury increased by 1.47 with every $1 \mathrm{~cm}$ extra achieved $(\mathrm{OR}=1.47$, 95\% CI 1.02 to 2.12, $\mathrm{p}=0.04) .{ }^{68} \mathrm{~A}$ functional leg length discrepancy of $>1.8$ $\mathrm{cm}$ was also found to be a risk factor for hamstring muscle strain-type injuries $(\mathrm{OR}=3.80,95 \%$ CI 1.08 to 13.33, $\mathrm{p}=0.03){ }^{62}$

Measured factors that did not significantly correlate with injury or recurrent injury included level of abdominal strength, $\mathrm{VO}^{2} \max$ results, various measures of anaerobic fitness ${ }^{1}$ pain provocation test, time to ascend stairs pain-free, mechanism of injury, ${ }^{76}$ maximal average power, counter movement jump (CMJ), CMJ on one leg, standing jump, peak $\mathrm{O}^{2}$ uptake, player exposure, ${ }^{53}$ jumping ability, running speed ${ }^{61}$ and knee laxity asymmetry. ${ }^{62}$

\section{Ethnicity}

Three studies evaluated the ethnic origin of athletes as a potential risk factor. Two studies found an association with a significantly increased risk in players of Aboriginal descent $(p=0.04),{ }^{75}$ and players of black origin $(p<0.05) .{ }^{79}$ One study found no significant difference in incidence of hamstring injuries as a function of ethnic origin. 57

\section{Work rate}

Two studies did not show any significant findings for a difference in the amount of time spent in training and games ${ }^{78}$ and frequency of off season running $(p=0.14) .{ }^{65}$

\section{Type of activity}

A significantly higher proportion $(68 \%, \mathrm{p}=0.00)$ of hamstring muscle strain-type injuries were sustained during running activities than during any other activity, but the highest severity injuries were sustained during kicking. ${ }^{57}$

\section{DISCUSSION}

The risk factors most consistently associated with hamstring muscle strain-type injuries were age, previous hamstring injury and quadriceps peak torque. Some risk factors require further research to adequately clarify their involvement due to inconclusive results, small sample sizes or very few studies on their influence. These risk factors include hamstring flexibility (measured via the AKE test), weight, hip flexor flexibility, quadriceps flexibility, ankle dorsiflexion lunge ROM, playing position, proprioception (movement discrimination test), mental imagery, ethnicity, hamstring peak torque (strength) and $\mathrm{H}: \mathrm{H}$ ratio.

The results of this review showed that there are many risk factors that appear to have little correlation with hamstring muscle strain-type injuries. These were BMI, height, passive length of hamstring, dominant limb, abdominal strength, $\mathrm{VO}^{2}$ max, various measures of anaerobic fitness, pain provocation test, time to ascend stairs pain-free, slump test, mechanism of injury, maximal average power, CMJ, CMJ on one leg, standing jump, peak $\mathrm{O}^{2}$ uptake, player exposure, jumping ability, knee laxity and running speed.

Three other systematic reviews ${ }^{9} 1083$ all found hamstring strength to be a risk factor. The meta-analysis in this review does not fully support their findings. Foreman et $a l^{9}$ and Prior et $a l^{10}$ both associated hamstring muscle strain-type injuries with decreased hamstrings flexibility and previous injury. This review does not support hamstrings flexibility as a risk factor due to conflicting evidence and the meta-analysis did not demonstrate a significant relationship between AKE test results and hamstring injury, although this analysis was approaching significance $(p=0.08)$. All three reviews found previous history of hamstring injury to be significant, which is supported by the findings from the present review.

The study by Arnason et $a l^{53}$ appeared to be a factor in the heterogeneity in the meta analysis for risk factors such as age, BMI, weight and hamstring flexibility (measured via the PKE test). This study was of high quality and involved elite-level soccer players, however the large age range (16-38 years) of the participants may have contributed to the heterogeneous findings. The spread in the age perhaps led to a greater difference shown between injured and non-injured groups, which potentially demonstrates that the risk of injury continues to increase as age increases and that there is an important relationship between age, BMI and flexibility. A meta-analysis cannot compensate for inadequacies in the original data extracted from the studies. There is the possibility for error in the meta-analysis calculations and despite a random effects model being used, heterogeneity may still be a problem.

The large number of variables examined results in a complicated picture of risk profile for hamstring muscle strain-type injuries. The tendency to assess the variables in isolation may further confound the picture, since important interactions between variables may be missed and the influence of some risk factors may be overstated. The findings from this review highlight that the factors of age and previous hamstring injury must be considered alongside any other risk factors being examined. The interaction between risk factors is likely important, since hamstring muscle strain-type injury is considered to be a multifactorial problem. ${ }^{9}$

\section{CONCLUSION}

The evidence demonstrates that older age, increased quadriceps peak torque and past history of hamstring injury were associated with increased risk of hamstring muscle strain-type injuries in sport. Further research is required using multivariate models to identify which factors are inter-related. This information could assist researchers to develop effective 
intervention programmes to prevent these injuries from occurring and decrease their impact on primarily the athletes but also their respective teams.

\section{What is already known on this topic?}

- Hamstring muscle strain injuries (HMSI) are common in sport and there is a high rate of recurrence. Many papers have examined potential risk factors for HMSI, with age and previous hamstring strain being accepted as risk factors, and many others inconsistently identified as contributing to the injury. Qualitative reviews have been undertaken on this topic, but a meta-analysis of risk factor studies has not been performed.

\section{What this study adds?}

- Meta-analysis identified age, previous history of hamstring strain and increased quadriceps peak torque as risk factors for HMSI. Other strength measures such as hamstring: quadriceps ratio, commonly perceived to be predictive of injury, were not associated with HMSI. This study highlights risk factors that require further investigation to confirm their involvement in HMSI and risk factors that have no association and need not be tested in future studies.

\section{Competing interests None.}

Provenance and peer review Not commissioned; externally peer reviewed.

\section{REFERENCES}

1 Orchard J, Marsden J, Lord S, et al. Preseason hamstring muscle weakness associated with hamstring muscle injury in Australian footballers. Am J Sports Med 1997;25:81-5

2 Devlin L. Recurrent posterior thigh symptoms detrimental to performance in rugby union: predisposing factors. Sports Med 2000;29:273-87.

3 Drezner JA. Practical management: hamstring muscle injuries. Clin J Sport Med 2003;13:48-52.

4 Orchard J, Seward H. The AFL Injury Report 2008. Australian Football League 2008

5 Upton PA, Noakes TD, Juritz JM. Thermal pants may reduce the risk of recurrent hamstring injuries in rugby players. Br J Sports Med 1996;30:57-60.

6 Orchard J, Seward H. 2010 Injury Report. Australian Football league, 2010. http:/l mm.afl.com.au/portals/0/2010/aflinjuryreport2010_final.pdf (accessed 5 May 2011)

7 Petersen J, Thorborg K, Nielsen MB, et al. Acute hamstring injuries in Danish elite football: a 12-month prospective registration study among 374 players. Scand J Med Sci Sports 2010;20:588-92.

8 Hawkins RD, Hulse MA, Wilkinson C, et al. The association football medical research programme: an audit of injuries in professional football. Br J Sports Med 2001;35:43-7.

9 Foreman TK, Addy T, Baker $\mathrm{S}$, et al. Prospective studies into the causation of hamstring injuries in sport: a systematic review. Phys Ther Sport 2006;7:101-9.

10 Prior M, Guerin M, Grimmer K. An evidence-based approach to hamstring strain injury: a systematic review of the literature. Sports Health 2009;1:154-64.

11 Murray J, Farrington DP, Eisner MP. Drawing conclusions about causes from systematic reviews of risk factors: the Cambridge quality checklists. J Exp Criminol 2009:5:1-23.

12 Downs SH, Black N. The feasibility of creating a checklist for the assessment of the methodological quality both of randomised and non-randomised studies of health care interventions. J Epidemiol Community Health 1998;52:377-84.

13 Irving DB, Cook JL, Menz HB. Factors associated with chronic plantar heel pain: a systematic review. J Sci Med Sport 2006;9:11-22.

14 Oxman AD, Cook DJ, Guyatt GH. Users' guides to the medical literature. VI. How to use an overview. Evidence-Based Medicine Working Group. JAMA 1994:272:1367-71.

15 Cooper H, Hedges LV. The Handbook of Research Synthesis. New York: Russell Sage Foundation 1994
16 Higgins JP, Thompson SG, Deeks JJ, et al. Measuring inconsistency in meta-analyses. BMJ 2003;327:557-60.

17 Carlson C. The natural history and management of hamstring injuries. Curr Rev Musculoskelet Med 2008;1:120-3.

18 Clark RA. Hamstring injuries: risk assessment and injury prevention. Ann Acad Med Singap 2008;37:341-6.

19 Comfort $\mathrm{P}$, Green CM, Matthews M. Training considerations after hamstring injury in athletes. Strength Cond J 2009;31:68-74.

20 Donaldson CT, Dreese JC. Hamstring and quadriceps injuries. Curr Opin Orthop 2006:17:145-8.

21 Hoskins WT, Pollard H. Injuries in Australian rules football: a review of the literature. Australas Chiropr Osteopathy 2003;11:49-56.

22 Mann G, Shabat S, Friedman A, et al. Hamstring injuries. Orthopedics 2007:30:536-40.

23 Proske U, Morgan DL, Brockett $\mathrm{CL}$, et al. Identifying athletes at risk of hamstring strains and how to protect them. Clin Exp Pharmacol Physiol 2004;31:546-50.

24 Sole G, Milosavljevic S, Sullivan $S$, et al. Running-related hamstring injuries: a neuromuscular approach. Phys Ther Rev 2008;13:102-10.

25 Burkett LN. Causative factors in hamstring strains. Med Sci Sports 1970;2: 39-42.

26 Wallden M, Walters N. Does lumbo-pelvic dysfunction predispose to hamstring strain in professional soccer players? J Bodywork Mov Ther 2005;9:99-108.

27 Askling C, Saartok T, Thorstensson A. Type of acute hamstring strain affects flexibility, strength, and time to return to pre-injury level. Br J Sports Med 2006:40:40-4.

28 Emery CA, Meeuwisse WH, Hartmann SE. Evaluation of risk factors for injury in adolescent soccer: implementation and validation of an injury surveillance system. Am J Sports Med 2005;33:1882-91

29 Faude 0 , Junge A, Kindermann W, et al. Injuries in female soccer players: a prospective study in the German national league. Am J Sports Med 2005;33:1694-700.

30 Gabbett TJ, Domrow N. Risk factors for injury in subelite rugby league players. Am J Sports Med 2005;33:428-34.

31 Gabbett T, Minbashian A, Finch C. Influence of environmental and ground conditions on injury risk in rugby league. J Sci Med Sport 2007;10:211-8.

32 Greig M, Siegler JC. Soccer-specific fatigue and eccentric hamstrings muscle strength. J Ath/ Train 2009;44:180-4.

33 Lehance C, Binet J, Bury T, et al. Muscular strength, functional performances and injury risk in professional and junior elite soccer players. Scand J Med Sci Sports 2009;19:243-51.

34 Small K, McNaughton L, Greig M, et al. The effects of multidirectional soccer-specific fatigue on markers of hamstring injury risk. J Sci Med Sport 2010;13:120-5.

35 Söderman K, Alfredson H, Pietilä T, et al. Risk factors for leg injuries in female soccer players: a prospective investigation during one out-door season. Knee Surg Sports Traumatol Arthrosc 2001;9:313-21.

36 Ekstrand J, Hägglund $M$, Waldén $M$. Injury incidence and injury patterns in professional football: the UEFA injury study. Br J Sports Med 2011;45:553-8.

37 Elliott MC, Zarins B, Powell JW, et al. Hamstring muscle strains in professional football players: a 10-year review. Am J Sports Med 2011;39:843-50.

38 Brockett CL, Morgan DL, Proske U. Predicting hamstring strain injury in elite athletes. Med Sci Sports Exerc 2004;36:379-87.

39 Emery CA. Risk factors for injury in child and adolescent sport: a systematic review of the literature. Clin J Sport Med 2003;13:256-68.

40 Satterthwaite $\mathrm{P}$, Norton $\mathrm{R}$, Larmer $\mathrm{P}$, et al. Risk factors for injuries and other health problems sustained in a marathon. Br J Sports Med 1999;33:22-6.

41 Small K, McNaughton LR, Greig M, et al. Soccer fatigue, sprinting and hamstring injury risk. Int J Sports Med 2009;30:573-8.

42 Waldén $M$, Hägglund $M$, Ekstrand J. UEFA Champions League study: a prospective study of injuries in professional football during the 2001-2002 season. Br J Sports Med 2005:39:542-6.

43 Kim D, Hong J. Hamstring to quadriceps strength ratio and noncontact leg injuries: A prospective study during one season. Isokinet Exerc Sci 2011; 19:1-6.

44 Croisier JL, Forthomme B, Namurois MH, et al. Hamstring muscle strain recurrence and strength performance disorders. Am J Sports Med 2002;30:199-203.

45 Steffen K, Myklebust G, Andersen TE, et al. Self-reported injury history and lower limb function as risk factors for injuries in female youth soccer. Am J Sports Med 2008;36:700-8.

46 Engebretsen $\mathrm{AH}$, Myklebust G, Holme I, et al. Risk factors for ankle, knee, hamstring and groin injuries among male football players: a prospective cohort study. Br J Sports Med 2008;42:493-4.

47 Hagel B. Hamstring injuries in Australian football. Clin J Sport Med 2005; 15:400

48 Sattler T. Intrinsic risk factors for sport injuries in female volleyball. Br J Sports Med 2011:45:533-4

49 Blake C, Murphy JC, Gissane C, et al. A prospective study of injury in elite gaelic games. Br J Sports Med 2011:45:337.

50 Black players at higher risk of hamstring strain. Physiotherapy Frontline 2004;10:12. 
51 Graham-Smith $P$, Lees $A$. Risk assessment of hamstring injury in rugby union place kicking. In: Spinks W, Reilly T, Murphy A, editors. Science and Football IV. London: Routledge. Taylor \& Francis Group 2002. pp 182-89.

52 Schache AG, Crossley KM, Macindoe IG, et al. Can a clinical test of hamstring strength identify football players at risk of hamstring strain? Knee Surg Sports Traumatol Arthrosc 2011;19:38-41.

53 Arnason A, Tenga A, Engebretsen L, et al. A prospective video-based analysis of injury situations in elite male football: football incident analysis. Am J Sports Med 2004;32:1459-65.

54 Bennell K, Tully E, Harvey N. Does the toe-touch test predict hamstring injury in Australian Rules footballers? Aust J Physiother 1999;45:103-9.

55 Bennell $\mathrm{K}$, Wajswelner $\mathrm{H}$, Lew $\mathrm{P}$, et al. Isokinetic strength testing does not predict hamstring injury in Australian Rules footballers. Br J Sports Med 1998;32:309-14.

56 Bradley PS, Portas MD. The relationship between preseason range of motion and muscle strain injury in elite soccer players. J Strength Cond Res 2007;21:1155-9.

57 Brooks JH, Fuller CW, Kemp SP, et al. Incidence, risk, and prevention of hamstring muscle injuries in professional rugby union. Am J Sports Med 2006;34:1297-306.

58 Cameron M, Adams R, Maher C. Motor control and strength as predictors of hamstring injury in elite players of Australian football. Phys Ther Sport 2003;4:159-66.

59 Christensen C, Wiseman D. Strength, The common variable in hamstring strain. J Athlet Train 1972;7:36-40.

60 Croisier JL, Ganteaume S, Binet J, et al. Strength imbalances and prevention of hamstring injury in professional soccer players: a prospective study. Am J Sports Med 2008:36:1469-75.

61 Engebretsen AH, Myklebust G, Holme I, et al. Intrinsic risk factors for hamstring injuries among male soccer players: a prospective cohort study. Am I Sports Med 2010;38:1147-53.

62 Fousekis K, Tsepis E, Poulmedis $\mathrm{P}$, et al. Intrinsic risk factors of non-contact quadriceps and hamstring strains in soccer: a prospective study of 100 professional players. Br J Sports Med 2011:45:709-14.

63 Gabbe BJ, Bennell KL, Finch CF. Why are older Australian football players at greater risk of hamstring injury? J Sci Med Sport 2006;9:327-33.

64 Gabbe BJ, Bennell KL, Finch CF, et al. Predictors of hamstring injury at the elite level of Australian football. Scand J Med Sci Sports 2006;16:7-13.

65 Gabbe BJ, Finch CF, Bennell KL, et al. Risk factors for hamstring injuries in community level Australian football. Br J Sports Med 2005;39:106-10.

66 Gibbs NJ, Cross TM, Cameron M, et al. The accuracy of MRI in predicting recovery and recurrence of acute grade one hamstring muscle strains within the same season in Australian Rules football players. J Sci Med Sport 2004;7:248-58.

67 Hägglund M, Waldén M, Ekstrand J. Previous injury as a risk factor for injury in elite football: a prospective study over two consecutive seasons. Br J Sports Med 2006;40:767-72.
68 Henderson G, Barnes CA, Portas MD. Factors associated with increased propensity for hamstring injury in English Premier League soccer players. J Sci Med Sport 2010:13:397-402.

69 Koulouris G, Connell DA, Brukner $P$, et al. Magnetic resonance imaging parameters for assessing risk of recurrent hamstring injuries in elite athletes. Am J Sports Med 2007;35:1500-6.

70 Malliaropoulos N, Isinkaye T, Tsitas K, et al. Reinjury after acute posterior thigh muscle injuries in elite track and field athletes. Am J Sports Med 2011;39:304-10.

71 Orchard JW. Intrinsic and extrinsic risk factors for muscle strains in Australian football. Am J Sports Med 2001:29:300-3.

72 Rolls A, George K. The relationship between hamstring muscle injuries and hamstring muscle length in young elite footballers. Phys Ther Sport 2004:5:179-87.

73 Sugiura Y, Saito T, Sakuraba K, et al. Strength deficits identified with concentric action of the hip extensors and eccentric action of the hamstrings predispose to hamstring injury in elite sprinters. J Orthop Sports Phys Ther 2008;38:457-64.

74 Verrall GM, Slavotinek JP, Barnes PG, et al. Assessment of physical examination and magnetic resonance imaging findings of hamstring injury as predictors for recurrent injury. J Orthop Sports Phys Ther 2006;36:215-24.

75 Verrall GM, Slavotinek JP, Barnes PG, et al. Clinical risk factors for hamstring muscle strain injury: a prospective study with correlation of injury by magnetic resonance imaging. Br J Sports Med 2001:35:435-9.

76 Warren P, Gabbe BJ, Schneider-Kolsky M, et al. Clinical predictors of time to return to competition and of recurrence following hamstring strain in elite Australian footballers. Br J Sports Med 2010;44:415-9.

77 Watsford ML, Murphy AJ, McLachlan KA, et al. A prospective study of the relationship between lower body stiffness and hamstring injury in professional Australian rules footballers. Am J Sports Med 2010;38:2058-64.

78 Witvrouw E, Danneels L, Asselman P, et al. Muscle flexibility as a risk factor for developing muscle injuries in male professional soccer players. A prospective study. Am J Sports Med 2003:31:41-6.

79 Woods C, Hawkins RD, Maltby S, et al. The Football Association Medical Research Programme: an audit of injuries in professional football-analysis of hamstring injuries. Br J Sports Med 2004;38:36-41.

80 Yamada $\mathrm{M}$, Mastumoto $\mathrm{D}$. The reaction time of mental rotation predicts strain in rugby players. J Phys Ther Sci 2009;21:177-82.

81 Yamamoto T. Relationship between hamstring strains and leg muscle strength: a follow-up study of collegiate track and field athletes. J Sport Med Phys Fit 1993;33.

82 Yeung SS, Suen AM, Yeung EW. A prospective cohort study of hamstring injuries in competitive sprinters: preseason muscle imbalance as a possible risk factor. $\mathrm{Br} \mathrm{J}$ Sports Med 2009;43:589-94.

83 Emery CA. Does decreased muscle strength cause acute muscle strain injury in sport? A systematic review of the evidence. Phys Ther Rev 1999;4:141-51. 